\title{
Integração da tomografia sísmica de refração e da análise multicanal de ondas superficiais na investigação rasa na região de Termas de lbirá, estado de São Paulo, Brasil
}

Thiago Fonseca Fraga e Renato Luiz Prado, Universidade de São Paulo

Copyright 2016, SBGf - Sociedade Brasileira de Geofísica

Este texto foi preparado para a apresentação no VII Simpósio Brasileiro de Geofísica, Ouro Preto, 25 a 27 de outubro de 2016. Seu conteúdo foi revisado pelo Comitê Técnico do VII SimBGf, mas não necessariamente representa a opinião da SBGf ou de seus associados. É proibida a reprodução total ou parcial deste material para propósitos comerciais sem prévia autorização da SBGf.

\section{Resumo}

Os métodos sísmicos de refração e/ou reflexão são bastante utilizados para o estudo do meio geológico. Ambos baseiam-se na análise das ondas de corpo, porém os sismogramas obtidos usualmente contêm registros muito notáveis das ondas superficiais (groundroll). Este trabalho apresenta a integração dos métodos tomografia sísmica de refração e análise multicanal de ondas superfíciais (MASW), analisando os diferentes campos de ondas dos mesmos registros sísmicos obtidos em uma aquisição de dados padrão para a sísmica de refração. O estudo proposto foi realizado na região de Termas de Ibirá.

\section{Introdução}

Os métodos sísmicos são amplamente utilizados para o estudo do meio geológico. Através de registros de tempo de percurso da onda elástica, diversos métodos de análise e processamento foram desenvolvidos para determinar diferentes características desse meio.

Dentre os métodos desenvolvidos estão os métodos de sísmica de refração (Palmer, 1980; Podvim e Lecomte 1991, 2000), sísmica de reflexão (Mayne, 1962; Yilmaz, 1980), sísmica entre furos (crosshole), análise multicanal de ondas superficiais (Park, 1998; Xia, 1999).

Cada um desses métodos foca em um único campo de onda, sendo os demais campos de onda também são registrados considerados "ruídos coerentes". Por exemplo, métodos sísmicos de refração utilizam majoritariamente apenas 0 campo das ondas $P$ refratadas.

Ensaios de sísmica de reflexão se utilizam da reflexão de ondas P, majoritariamente, ou das ondas S (Guy et al, 2003; Bexfield et al, 2006). O MASW utiliza o campo das ondas superficiais, especificamente as ondas Rayleigh. Através desse método é possível mapear a distribuição das velocidades das ondas S com a profundidade (Xia et al., 2002; 2003).

Os métodos sísmicos de refração, reflexão e MASW empregam na aquisição dos dados geometrias de campo similares, ou seja, a configuração dos geofones e pontos de tiro são parecidas. Podemos, então, após uma análise prévia da resposta do meio através do ensaio padrão de análise de ruídos determinar parâmetros de campo que possam resultar no melhor registro de todos os campos de ondas em uma única aquisição.-Foi essa a motivação principal deste estudo realizar uma aquisição de dados visando à integração dos métodos sísmicos de refração e MASW, ou seja, extrair informação, em uma mesma aquisição, do campo de onda refratado e do campo de onda de superfície Rayleigh. A integração de métodos possibilita a obtenção de um modelo geológico. Apesar de existirem trabalhos com integração de métodos sísmicos (Sloan et al, 2013; Ouellet e Fortier, 2014), sua abordagem não é recorrente. Representa uma tendência mais recente da sísmica de exploração rasa buscando a obtenção de modelos mais completos de subsuperficie.

\section{Metodologia}

A região de Termas de Ibirá está localizada a noroeste da capital do estado de São Paulo, assentada sobre a Bacia do Paraná onde predominam rochas pertencentes às Supersequências Gondwana III e Bauru (Couto Jr, 2015). Na região de Termas de lbirá verifica-se a ocorrência dos arenitos do Grupo Bauru, arenitos característicos de deposição eólica em ambiente desértico flúvio/lacustre (Milani et al, 2007; Couto Jr, 2015). O embasamento dos arenitos corresponde aos derrames basálticos da formação Serra Geral pertencentes à Supersequencia Gondwana III (Milani et al, 2007 e Couto Jr, 2015).

Os métodos integrados nesse trabalho para o estudo da área foram os métodos de tomografia sísmica de refração e MASW. A Tomografia sísmica por tempo de percurso é baseada na discretização da subsuperfície, criando células por onde passam os raios sísmicos. Através da utilização de algoritmo iterativos obtêm-se um modelo de subsuperfície. A tomografia, comparativamente aos métodos recíprocos, lida melhor com situações geológicos onde se observa um aumento gradativo da velocidade com a profundidade.

O software Rayfract ${ }^{\circledR}$ utilizado nesse trabalho, funciona resolvendo a Equação Eikonal por diferenças finitas (Lecomte e Podvin, 1991). Os trajetos dos raios, são traçados pela determinação da primeira zona de Fresnel (Watanabe, 1999) e se baseia no princípio de Huygens considerando além do caminho, a influência das estruturas próximas.

O método MASW é baseado no fenômeno da dispersão das ondas superficiais, e visa à obtenção de modelos da distribuição vertical das velocidades da onda cisalhante no subsolo (Strobbia, 2002). O modelo é obtido a partir da inversão da imagem de dispersão extraída a partir do processamento do campo de onda registrado nos dados.

\section{Aquisição e Processamento}

Existem vários arranjos de aquisição para os métodos sísmicos, entretato, para satisfazer o objetivo proposto a aquisição dos dados utilizou o arranjo comum da sísmica de refração. Foram utilizados 96 geofones de $14 \mathrm{~Hz} \mathrm{com}$ 
espaçamento de 2 metros (Figura 1). Usualmente para o método MASW são utilizados geofones de frequências menores, porém os geofones utilizados apresentaram-se promissores para análise. A fonte utilizada foi a marreta sísmica com 21 pontos de tiro à cada 12 metros.

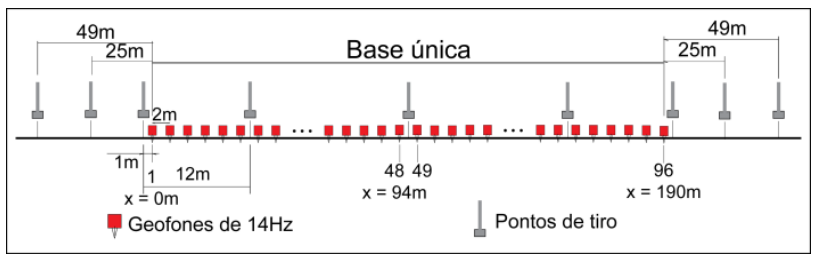

Figura 1: Arranjo de aquisição de campo com 96 geofones, espaçamento de 2 metros e ponto de tiro à cada 12 metros.

Após a aquisição os dados foram analisados por dois métodos distintos: tomografia sísmica de refração e MASW Os dados foram interpretados utilizando o software Rayfract ${ }^{\circledR}$ para a análise de refração, enquanto para a análise MASW foi utilizado o Surfseis $\AA$. A relação sinal/ruído foi boa sendo utilizado apenas o ganho AGC (automatic gain control) para melhor identificação do tempo de chegada em cada geofone.

Através do software é possível obter resultados tanto para tomografia sísmica de refração como método recíproco. Utilizando o método Delta-t-V de Gebrand \& Miller (1985) para criação do modelo inicial de velocidade e profundidade para a inversão dos dados.

O processamento dos dados pelo método MASW consiste em extrair dos registros sísmicos as velocidades de fase da onda Rayleigh em função da frequência para a obtenção de uma imagem de dispersão. Da imagem de dispersão uma curva de dispersão é extraída utilizando os máximos de energia (Foti, 2003). Após extrair a curva de dispersão inicia-se o processo de inversão, ou seja, a análise da curva comparando-a de forma iterativa com modelos estratigráficos de espessura, velocidade e densidades (Xia et al, 1999). O resultado da inversão é um modelo de variação da velocidade da onda $S$ em subsuperfície devido à sua contribuição mais significativa com a variação da onda Rayleigh (Xia et al, 1999).

\section{Resultados e Discussão}

O resultado obtido através da tomografia sísmica de refração é apresentado na figura 2. As interfaces são inferidas pelo contraste de velocidade da onda sísmica (Figura 2.a). Também é apresentado a densidade de raios dos tiros dados ao longo da seção resultantes do processo de inversão (Figura 2.b).

Analisando o comportamento da velocidade da onda $P$, solos não compactados e materiais inconsolidados apresentam em geral velocidades maiores que $350 \mathrm{~m} / \mathrm{s}$ e menores que $900 \mathrm{~m} / \mathrm{s}$. Assim, pode-se inferir uma primeira interface por volta de 12 metros de profundidade quase paralela à superfície separando 0 solo não consolidado de um solo mais compacto ou possível alteração de rocha. Também, por volta de 23 metros de profundidade deve-se encontrar o arenito mais são com velocidades superiores à $2000 \mathrm{~m} / \mathrm{s}$.

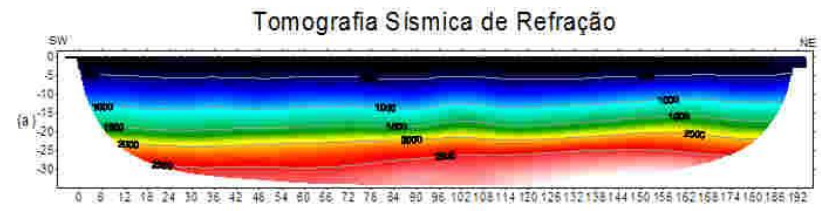

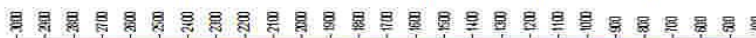

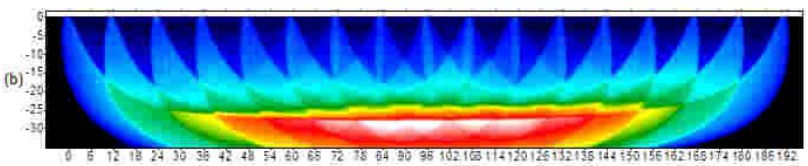

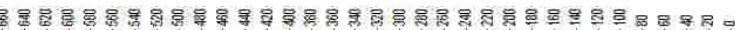

Figura 2: Seção de tomografia sísmica de refração (a) e densidade de raios dos tiros dados ao longo da seção sísmica.

Pelo método recíproco um único refrator foi identificado confirmando a interface por volta de 12 metros. A velocidade da camada de solo obtida foi de $500 \mathrm{~m} / \mathrm{s}$ enquanto a segunda camada possui velocidade entre $2000 \mathrm{~m} / \mathrm{s}$ e $3000 \mathrm{~m} / \mathrm{s}$. A seção de tomografia não apresentou estimativa do basalto, porém utilizando os tiros externos ao arranjo através do método recíproco pode-se estimar uma segunda interface por volta de 65 metros com velocidade compatível com 0 basalto $(5200 \mathrm{~m} / \mathrm{s})$.

O resultado obtido através do método de análise multicomponente de ondas superficiais é apresentado na figura 3.

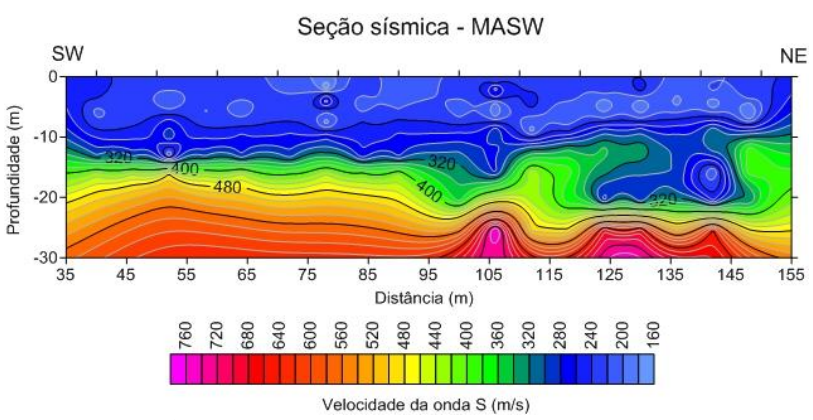

Figura 3: Seção de análise multicomponente de ondas superficiais (MASW).

O perfil indica a presença de uma interface por volta de 13 metros com velocidade aproximada de $320 \mathrm{~m} / \mathrm{s}$. Essa camada corresponde a camada de solo presente também na tomografia sísmica.

\section{Conclusões}

Separadamente os resultados apresentam por vezes as mesmas interfaces, porém podem complementar com informações que não se apresentam em outro método. Por exemplo a identificação do basalto apenas por meio do método recíproco. Assim a integração dos métodos pode apresentar um modelo mais completo do local estudado. Apesar do resultado apresentado separadamente, espera-se obter uma seção integrada com um modelo mais completo de subsuperfície. 
Com os perfis de velocidades $\mathrm{P}$ e $\mathrm{S}$, também será possível obter um modelo do comportamento do coeficiente de poisson em subsuperfície. O conhecimento desse modelo pode auxiliar na obtenção de constantes elásticas, informação importante para obras de engenharia.

Com alguma modificação no arranjo de campo, também é possível fazer uma análise de sísmica de reflexão com os dados, o que poderia trazer informações novas para a seção, porém estudos prévios não apresentaram potencial para esse tipo de análise.

\section{Agradecimentos}

Agradeço ao Instituto de Astronomia, Geofísica e Ciência Atmosférica da Universidade de São Paulo por todo apoio.

\section{Referências}

Couto Jr., M. A., 2015. Caracterização hidrogeoelétrica na região de Termas de lbirá, Bacia do Paraná, por meio de inversão conjunta 1D de sodagens TDEM/SEVs. Dissertação de mestrado. Instituto de Astronomia Geofísica e Ciências Atmosféricas da Universidade de São Paulo. Pp.1-166.

Foti, S., 2003. Surface wave methods for soil characterisation. UPC Barcelona. Pp 1-45.

Guy, E.D., Nolen-Hoeksema, R.C., Daniels, J.J., Lefchik, $\mathrm{T}$., 2003. High-resolution $\mathrm{SH}$-wave seismic reflection investigations near a coal mine-related roadway collapse feature. J. Appl. Geophys. 54 (1), 51-70

Milani, E. J., Melo, J. H. G. de, Souza, P. A., Fernandes, L. A., França, A. B. 2007. Bacia do Paraná. B. Geoci. Petrobras, Rio de Janeiro, v. 15, n. 2, p. 265-287.

Ouellet, G. F., Fortier, R. 2014. Using all seismic arrivals in shallow seismic investigations. Journal of Applied Geophysics 103 (2014) 31-42.

Palmer, D., 1981. An introduction to the generalized reciprocal method of seismic refraction interpretation. Geophysics 46 (11), 1508-1518.

Xia, J.; Miller, R.D.; Park, C.B., 1999. Estimation of nearsurface shear-wave velocity by inversion of Rayleigh waves. Geophysics, v.64, n.3. p.691-700.

Watanabe, T., Matsuoka, T., Ashida, Y. 1999. Seismic traveltime tomography using Fresnel volume approach. Society of Exploration Geophysics. Pp. 1-4. 